\title{
Supplementing different levels of Saccharomyces cerevisiae diets on survival and some growth parameters in laboratory reared Heteroclarias juveniles
}

Ayanwale, A. V., Ogbonnaya, E. C., Arimoro, F. O., Unique, N. K. and

Chukwuemeka, V. I.

Department of Animal Biology,

Federal University of Technology, Minna, Nigeria.

Corresponding author: a.adesola@futminna.edu.ng ; +2348036532471

Abstract

An eight weeks feeding trial was carried out to evaluate the influence of supplementing different levels of Saccharomyces cerevisiae in diets on survival rates and some growth parameters of Heteroclarias juveniles under laboratory conditions. S. cerevisiae was included in the diets at 4 levels of 0.00 (control: Aquamax), 5.00, 10.00 and 15.00\% with 3 replicates each. Each of the experimental tanks was filled with 25 litres of borehole water and stocked with 30 randomly selected juveniles of Heteroclarias. The growth and physicochemical parameters were determined weekly, while survival rates were monitored daily using standard experimental procedures. Exchange of water was done twice a week during the study period. The juveniles were fed to satiation daily in the morning and evening. The proximate analysis of S.cerevisiae supplemented diets fed to Heteroclarias juveniles were higher in moisture composition. The results of the mean total length and standard length showed that there were no significant $(p>0.05)$ differences between the juveniles fed the control diet and the S. cerevisiae diets. However, mean body weight were influenced ( $p<$ $0.05)$ with juveniles fed $10 \% \mathrm{~S}$. cerevisiae diet having better body weight (31.36 $4.13 \mathrm{~g})$ compared to the other treatments. The survival rate (97\%) of Heteroclarias juveniles fed with $5 \%$ S. cerevisiae level was significantly $(p<0.05)$ highest. Most of the physicochemical parameters of cultured water of Heteroclarias juveniles fed with all the diets were not affected ( $p>0.05)$; except the Biochemical Oxygen Demand (BOD) that was significantly $(p<0.05)$ different. Moisture ash, crude protein and oil extract were all significantly $(p<0.05)$ affected having lower ash and crude protein contents $(2.15 \pm 0.01$ and $45.00 \pm 0.58)$ respectively. The inclusion of $10 \% \mathrm{~S}$. cerevisiae in the diet of Heteroclarias juveniles improved growth performance.

Keywords: Influence, Saccharomyces cerevisiae, Diet, Growth parameters, Heteroclarias juveniles and Survival rate.

\section{Introduction}

One of the major constraints facing aquaculture in the developing world is on improving the efficiency of production through the provision of indigenous feed which can compete favourably well with imported or commercial diets. Moreover, the aquaculture industry is also faced with high mortality rates (among the fries or fingerlings), poor growth performance, poor immune response and inadequate supply of protein from fish sources. To meet these challenges and maintain efficient feed utilization, series of attempts have been made which include incorporation of antimicrobial and other natural products such as Direct Feed Microbials (DFM) into animal feeds (Buntyn et al., 2016). Irianto and Austin (2002) in their study reported that fortification of feeds with Baker's yeast (S. cerevisiae) will enhance fast growth, low cost and high stability in aquaculture. In addition, Taoka et al. (2006) also documented that the application of probiotics can improve feed conversion, growth rates and weight gain of fish 
including Clarias spp. Many beneficial attributes of live yeast improved diet have been identified to include protein digestibility which may explain the better growth and feed efficiency with fish supplements. Similarly, Santini et al. $\left(\begin{array}{llll}2 & 0 & 1 & 0\end{array}\right) \quad \mathrm{r}$ e p o r t e d $\mathrm{t} \mathrm{h}$ a t mannanoligosaccharides and fruit oligosaccharides in the cell wall of yeast such as $S$. cerevisiae maintain or reestablish the condition of eubiosis in the digestive tube and hence assist in gastrointestinal balance. Probiotics such as $S$. cerevisiae may include microbial additives that prevent pathogenic organisms from proliferating or establishing in the gut, thus, ensuring optimal use of feed by aiding digestion, improving water quality and stimulating the immune system of the host (Wang et al., 2004). The authors also observed that there is a suggestive evidence that several probiotics strains such as Lactobacillus acidophilus and S. cerevisiae are useful in boosting the immune response of animals. Similar to observations on imported yeast, the use of cheap local baker's yeast for African catfish also has been reported to increase growth and production under farming conditions (Mona et al., 2015). However, there is paucity in literature on the use of probiotics such as $S$. cerevisiae in the fortification of feed of Heteroclarias juveniles. Therefore, this study was carried out to evaluate the supplemental influence of different levels of $S$. cerevisiae diets on survival rates and some growth parameters of Heteroclarias juveniles under laboratory conditions.

\section{Materials and methods \\ Location}

The study was carried out in the Laboratory of the Department of Animal Biology of the School of Life Sciences, Federal University of Technology, Minna, Niger State. The location of the school is at latitude 9'31 and 40 North and longitude 6'31 and 6'45 East of the equator. The area exists within the Southern Guinea savannah vegetation zone of Nigeria having a mean temperature range that falls between $26^{\circ} \mathrm{C}$ and $38^{\circ} \mathrm{C}$ (NSADP, 2007).

\section{Source of experimental fish}

Four hundred and fifty (450) Heteroclarias juveniles of six (6) weeks old were purchased from the hatchery of Water Resources, Aquaculture and Fisheries Technology (WAFT) Fish farm, Bosso campus, located at Federal University of Technology Minna, Niger State. These juveniles were carefully transported to the Laboratory of Biological Sciences, Federal University of Technology Minna, Niger State in a well-ventilated bucket with 25 litres of water to reduce the risk of mortality.

\section{Acclimatization of the experimental fish}

Fifty (50) Heteroclarias juveniles were carefully and randomly distributed into prepared plastic aquaria tanks, each containing 25 litres of water. This was done so as to make them get used to their new environment, to confirm if there was any form of infection from the source of purchase and also to relieve them from overcrowding (Okeke, 2014). During this process, juveniles of the same size were kept in the same plastic holding tanks (Ayanwale et al., 2014). This was done to prevent cannibalism which may lead to mortality (Adewolu et al., 2008). During acclimatization, the fishes were fed to satiation twice daily with a conventional feed (Aquamax) according to Dong Han et al. (2005).

\section{Experimental design}

The experiment consisted of four (4) treatments with three (3) replicates each. Treatment 1 was control, while treatments 2, 3 and 4 were 5, 10 and $15 \%$ of Saccharomyces cerevisiae diets, respectively. The aquarium tanks were 
filled with 25 litres of borehole water and 30 Heteroclarias juveniles were carefully and randomly distributed in each tank. The experimental tanks were covered with nets to prevent the fish from jumping out (Olufayo, 2009). The experimental fish were kept off feed for a period of 24 hours before the commencement of the experiment (Ayanwale et al., 2014). The control juveniles were thereafter fed with the conventional diet while the other treatments were fed with the formulated diets. The Heteroclarias juveniles were fed to satiation every morning and evening (Dong Han et al., 2005). Exchange of water was done twice a week with fresh borehole water. The faecal materials and leftover feed were removed from the tanks after feeding (Ayanwale et al., 2014). The experiment lasted for a period of 8 weeks before termination.

Preparation of probiotics (Saccharomyces cerevisiae)

The Nutrient broth $(6.5 \mathrm{~g})$ was weighed into a $500 \mathrm{~mL}$ conical flask and diluted with $500 \mathrm{~mL}$ of distilled water so as to produce a homogenous solution. The solution was covered with cotton wool to serve as a stopper, wrapped with aluminum foil and tightened with masking tape. It was later sterilized by autoclaving at $121^{\circ} \mathrm{C}$ for 15 minutes. One (1.0) $\mathrm{g}$ of the commercial Baker's yeast was inoculated into a sterile water of $5 \mathrm{~mL}$ and shaken vigorously. A sterile syringe was used to draw $0.1 \mathrm{~mL}$ of the diluent (diluted solution) and then, dropped on a plate of Sabouraud Dextrose Agar (SDA), and streaked with a wireloop and incubated at ambient temperature for 24 hours. A loop-full of cultured Saccharomyces cerevisiae was then transferred into $500 \mathrm{~mL}$ of sterile nutrient broth. This was replicated three (3) other times to give a total of 2 litres of Baker's yeast culture. The plate was incubated at $25^{\circ} \mathrm{C}$ for 24 hours according to the method described by Association of Official Analytical Chemists (AOAC) 2006.

\section{Experimental diet formulation}

The diet formulation was done at the Laboratory of Water Resources, Aquaculture and Fisheries Technology, Federal University of Technology, Minna, Niger state. The diet was formulated using the Pearson square method of feed formulation. Foreign fish meal and yellow maize along with other ingredients were weighed using an electronic scale with model number SF-400. They were mixed in a bowl, then 5, 10, and $15 \mathrm{~g}$ of Saccharomyces cerevisiae were added respectively in different bowls. The weight of the fish meal and the yellow maize varied according to the concentration of the yeast. They were then pelleted using a manual pelleting machine for a duration of two (2) hours. The feeds were oven dried at a temperature of $60^{\circ} \mathrm{C}$ for 72 hours to reduce its moisture content so as to prevent spoilage (AOAC, 2006; Olagunju et al., 2007).

\section{Proximate composition}

The proximate composition of the Heteroclarias juveniles fed different levels of Saccharomyces cerevisiae was analysed according to the methods of AOAC (2006).

\section{Source of conventional diet}

Aquamax conventional diet produced by United African Company (UAC), Lagos Nigeria was used to feed the control juveniles. The feed Composition showed that it contained $42 \%$ crude protein, $12 \%$, Crude fat, $2.6 \%$ Crude fibre, $7.0 \%$ Ash, $12 \%$ moisture, $1.2 \%$ Phosphorus, $2.5 \%$ $\mathrm{Calcium}, 2.6 \%$ Lysine and $1.4 \% \mathrm{M}$ e $\mathrm{t}$ h i o $\mathrm{n}$ i $\mathrm{n}$ e.

\section{Determination of physico-chemical parameters}

\section{Water temperature}

This was achieved by using Mercury inbulb thermometer which was inserted 
vertically in the water for three (3) minutes and the reading was recorded. It was done in the morning hours by 9 a.m on a weekly basis for a period of 8 weeks (Ayanwale et al., 2014).

\section{Hydrogen ion concentration (pH)}

This was determined by the use of a portable digital $\mathrm{pH}$ meter. The $\mathrm{pH}$ meter was standardized using buffer solution of 7.02. It was inserted into each samples of the experimental tanks and was allowed to stabilize for 5 minutes before readings were taken. This was also done every morning hours by ( 9 am) on a weekly basis (Axiel, 2010).

\section{Dissolved Oxygen (DO)}

This was done in the morning hours by 9a.m on a weekly basis for a period of 8 weeks with the aid of a portable dissolved Oxygen meter with model number JPB607 . The DO meter was inserted into each aquaria tanks for 5 minutes and readings were recorded in $\mathrm{Mg} / \mathrm{L}$ ((Okeke, 2014).

\section{Biochemical Oxygen Demand (BOD)}

Water samples from various experimental tanks were collected using a $250 \mathrm{~mL}$ dissolved Oxygen bottles without bubbles and were incubated in the dark for 5 days. The dissolved Oxygen concentration was measured on the fifth day using the DO meter. BOD was calculated using the formula given by Ayanwale et al. (2014).

$\mathrm{BOD}(\mathrm{mg} / \mathrm{l})=\mathrm{D} 1-\mathrm{D} 5$

Where D1 = dissolved oxygen calculated on the first day and D2 = dissolved oxygen calculated on the fifth day.

\section{Determination of growth parameters Total length and standard length}

Five (5) Heteroclarias juveniles were randomly selected from each of the plastic aquaria tanks weekly by using a sieve. Each individual fish was placed with care on a plain paper so as to absorb the water on the fish specimen. Thereafter, the fish specimen was now placed on aluminum foil, and the lengths were measured using a transparent meter ruler graduated in centimeters $(\mathrm{cm})$. The total length was determined by measuring the distance from the mouth of the fish to the caudal fin, while, the standard length was determined by measuring the distance from the mouth of the fish to the caudal penduncle (Ayanwale et al., 2014). This procedure was repeated for each of the fish samples from all the replicates.

\section{Measurement of weight}

Five (5) Heteroclarias juveniles were randomly selected from each of the plastic aquaria tanks weekly by using a sieve. The fish were placed with care on a plain paper to absorb the water and the specimen fish was placed singly on a plastic petri dish cover whose weight was adjusted to zero and the weight of the fishes were determined using an electronic pocket scale; model EHA25 (Ayanwale et al., 2014). This procedure was repeated for each of the replicate.

\section{Survival rate percentage (SR \%)}

This was calculated using the formula of Adewolu et al. (2008) that;

$\mathrm{SR}(\%)=$

Total number of fish harvested $\quad \times 100$

Total number of fish stocked

\section{Data analysis}

The data collected were analysed for significant differences $(\mathrm{P}<0.05)$ using the analysis of variance (ANOVA) tool of Statistical Package for Social Sciences (SPSS). Duncan Multiple Range Test (Duncan, 1955) was used to separate the means where there were statistically significant differences $(\mathrm{P}<0.05)$.

\section{Results and discussion}

The total length (TL) of Heteroclarias juveniles fed different levels of Saccaharomyces cerevisiae diets are presented in the Table 1. The TL were not 


\section{Ayanwale, Ogbonnaya, Arimoro, Unique and Chukwuemeka}

significantly $(\mathrm{P}>0.05)$ affected by the inclusion of $S$. cerevisiae in the diets of the fish at weeks 1 and 3 . However, the TL were all significantly $(\mathrm{p}<0.05)$ affected at weeks $2,4,5,6,7$ and 8 of the experiment. At the end of the experiment, the mean TL were observed not to be affected $(\mathrm{P}>0.05)$ by the inclusion of $S$. cerevisiae in the diets of the juvenile fish.

Table 1: Mean \pm standard error of total length $(\mathrm{cm})$ of Heteroclarias juveniles fed different levels of Saccharomyces cerevisiae diets for a period of eight weeks

\begin{tabular}{lllll}
\hline Weeks & Control & $5 \%$ & $10 \%$ & $15 \%$ \\
\hline 1 & $10.39 \pm 0.28^{\mathrm{a}}$ & $10.29 \pm 0.29^{\mathrm{a}}$ & $10.12 \pm 0.33^{\mathrm{a}}$ & $10.09 \pm 0.29^{\mathrm{a}}$ \\
2 & $11.33 \pm 0.20^{\mathrm{a}}$ & $10.81 \pm 0.27^{\mathrm{b}}$ & $10.61 \pm 0.28^{\mathrm{b}}$ & $10.47 \pm 0.29^{\mathrm{b}}$ \\
3 & $11.99 \pm 0.41^{\mathrm{a}}$ & $11.36 \pm 0.39^{\mathrm{a}}$ & $12.13 \pm 0.35^{\mathrm{a}}$ & $11.13 \pm 0.35^{\mathrm{a}}$ \\
4 & $11.77 \pm 0.27^{\mathrm{b}}$ & $11.50 \pm 0.29^{\mathrm{b}}$ & $12.67 \pm 0.27^{\mathrm{a}}$ & $11.34 \pm 0.33^{\mathrm{b}}$ \\
5 & $12.75 \pm 0.47^{\mathrm{c}}$ & $13.18 \pm 0.68^{\mathrm{b}}$ & $14.51 \pm 0.43^{\mathrm{a}}$ & $12.13 \pm 0.27^{\mathrm{c}}$ \\
6 & $13.41 \pm 0.46^{\mathrm{b}}$ & $13.80 \pm 0.74^{\mathrm{b}}$ & $15.29 \pm 0.42^{\mathrm{a}}$ & $13.42 \pm 0.41^{\mathrm{b}}$ \\
7 & $14.17 \pm 0.42^{\mathrm{b}}$ & $15.10 \pm 0.31^{\mathrm{a}}$ & $15.59 \pm 0.46^{\mathrm{a}}$ & $14.08 \pm 0.49^{\mathrm{b}}$ \\
8 & $14.65 \pm 0.40^{\mathrm{c}}$ & $15.37 \pm 0.34^{\mathrm{b}}$ & $17.21 \pm 0.30^{\mathrm{a}}$ & $14.29 \pm 0.50^{\mathrm{c}}$ \\
Mean & $12.56 \pm 0.52^{\mathrm{a}}$ & $12.68 \pm 0.69^{\mathrm{a}}$ & $13.52 \pm 0.89^{\mathrm{a}}$ & $12.12 \pm 0.58^{\mathrm{a}}$ \\
\hline
\end{tabular}

Values followed by the same superscript alphabet on the same row are not significantly different at $\mathrm{P}>0.05$ level of significance. Values are presented in mean \pm standard error, Control $=$ Aquamaxconventional feed, $5 \%=5 \%$ of $S$. cerevisiae $; 10 \%=10 \%$ of $S$. cerevisiae; $15 \%=15 \%$ of $S$. cerevisiae.

The results of Standard Length (SL) of the juveniles of Heteroclarias fed different levels of $S$. cerevisiae diets are shown in Table 2. Similarly, the SL were not significantly $(\mathrm{P}>0.05)$ affected by the inclusion of $S$. cerevisiae in the diets of the fish at weeks 1 and 3 . However, the SL were all significantly $(\mathrm{p}<0.05)$ affected at weeks $2,4,5,6,7$ and 8 of the experiment. At the end of the experiment, the mean SL were observed not to be affected $(\mathrm{P}>0.05)$ by the inclusion of $S$. cerevisiae in the diets of the juvenile fish.

Table 2: Mean \pm standard error of standard length $(\mathrm{cm})$ of Heteroclarias juveniles fed different levels of $S$. cerevisiae diet for a period of eight $(8)$ weeks

\begin{tabular}{lllll}
\hline Week & Control & $5 \%$ & $10 \%$ & $15 \%$ \\
\hline 1 & $8.63 \pm 0.25^{\mathrm{ab}}$ & $8.65 \pm 0.26^{\mathrm{ab}}$ & $8.49 \pm 0.3^{\mathrm{ab}}$ & $9.09 \pm 0.65^{\mathrm{a}}$ \\
2 & $9.41 \pm 0.19^{\mathrm{a}}$ & $9.02 \pm 0.25^{\mathrm{a}}$ & $8.75 \pm 0.24^{\mathrm{b}}$ & $8.78 \pm 0.26^{\mathrm{b}}$ \\
3 & $10.13 \pm 0.35^{\mathrm{a}}$ & $9.55 \pm 0.33^{\mathrm{a}}$ & $10.13 \pm 0.39^{\mathrm{a}}$ & $9.47 \pm 0.34^{\mathrm{a}}$ \\
4 & $9.48 \pm 0.23^{\mathrm{a}}$ & $9.53 \pm 0.15^{\mathrm{a}}$ & $10.53 \pm 0.26^{\mathrm{b}}$ & $9.49 \pm 0.30^{\mathrm{a}}$ \\
5 & $10.63 \pm 0.41^{\mathrm{b}}$ & $10.57 \pm 0.38^{\mathrm{b}}$ & $12.39 \pm 0.41^{\mathrm{a}}$ & $10.09 \pm 0.24^{\mathrm{b}}$ \\
6 & $10.89 \pm 0.49^{\mathrm{b}}$ & $10.69 \pm 0.50^{\mathrm{b}}$ & $12.00 \pm 0.47^{\mathrm{a}}$ & $10.60 \pm 0.60^{\mathrm{b}}$ \\
7 & $11.97 \pm 0.37^{\mathrm{b}}$ & $12.83 \pm 0.24^{\mathrm{ab}}$ & $13.29 \pm 0.40^{\mathrm{a}}$ & $11.98 \pm 0.46^{\mathrm{b}}$ \\
8 & $12.87 \pm 0.35^{\mathrm{c}}$ & $13.29 \pm 0.38^{\mathrm{b}}$ & $15.57 \pm 0.26^{\mathrm{a}}$ & $12.30 \pm 0.52^{\mathrm{c}}$ \\
Mean & $10.50 \pm 0.50^{\mathrm{a}}$ & $10.52 \pm 0.61^{\mathrm{a}}$ & $11.39 \pm 0.85^{\mathrm{a}}$ & $10.23 \pm 0.46^{\mathrm{a}}$ \\
\hline
\end{tabular}

Values followed by the same superscript alphabet on the same row are not significantly different at $\mathrm{P}>0.05$ level of significance. Values are presented in mean \pm standard error, Control=Aquamax conventional feed; $5 \%=5 \%$ of $S$. cerevisiae; $10 \%=10 \%$ of $S$. cerevisiae; $15 \%=15 \%$ of $S$. cerevisiae.

The body weight of Heteroclarias juveniles fed different levels of $S$. cerevisiae diets is presented in the Table 3 . The mean body weight was affected $(\mathrm{p}<0.05)$ by the inclusion of S. cerevisiae in the diets of the Heteroclarias juveniles from week 1 to 8 of the experiment. But, the analysis of the entire weeks (1-8) showed that juveniles fed $10 \%$ S. cerevisiae had better body weight $(31.36 \pm 4.13 \mathrm{~g})$ followed by those fed the control $(24.35 \pm 1.38 \mathrm{~g})$ and the $5 \% S$. cerevisiae supplemented diet $(22.25 \pm$ $1.46 \mathrm{~g}$ ) while those fed $15 \%$ of S. cerevisiae diet had the least body weight (19.96 \pm $1.22 \mathrm{~g})$. 
Table 3 : Mean \pm standard error of body $w$ eight of Heteroclarias juveniles fed different level of Saccharomyces cerevisiae diet for a period of eight $(8)$ weeks

\begin{tabular}{lllll}
\hline Week & Control & $5 \%$ & $10 \%$ & $15 \%$ \\
\hline 1 & $19.04 \pm 0.75^{\mathrm{c}}$ & $20.80 \pm 1.07^{\mathrm{a}}$ & $20.21 \pm 1.15^{\mathrm{a}}$ & $17.02 \pm 0.98^{\mathrm{b}}$ \\
2 & $27.15 \pm 0.97^{\mathrm{a}}$ & $23.24 \pm 0.97^{\mathrm{b}}$ & $23.13 \pm 1.33^{\mathrm{b}}$ & $22.66 \pm 1.04^{\mathrm{c}}$ \\
3 & $21.13 \pm 2.32^{\mathrm{a}}$ & $16.01 \pm 1.33^{\mathrm{c}}$ & $19.79 \pm 1.70^{\mathrm{b}}$ & $15.80 \pm 1.57^{\mathrm{d}}$ \\
4 & $20.43 \pm 1.83^{\mathrm{b}}$ & $17.52 \pm 0.96^{\mathrm{c}}$ & $22.17 \pm 1.50^{\mathrm{a}}$ & $16.41 \pm 1.56^{\mathrm{d}}$ \\
5 & $23.66 \pm 2.37^{\mathrm{b}}$ & $21.97 \pm 1.52^{\mathrm{b}}$ & $34.58 \pm 2.71^{\mathrm{a}}$ & $18.92 \pm 1.42^{\mathrm{c}}$ \\
6 & $25.45 \pm 1.96^{\mathrm{b}}$ & $24.00 \pm 1.57^{\mathrm{b}}$ & $38.18 \pm 2.86^{\mathrm{a}}$ & $20.91 \pm 1.44^{\mathrm{c}}$ \\
7 & $27.91 \pm 1.67^{\mathrm{b}}$ & $26.41 \pm 1.25^{\mathrm{b}}$ & $42.14 \pm 3.24^{\mathrm{a}}$ & $22.60 \pm 1.31^{\mathrm{c}}$ \\
8 & $29.99 \pm 1.18^{\mathrm{b}}$ & $28.06 \pm 1.50^{\mathrm{b}}$ & $50.65 \pm 3.94^{\mathrm{a}}$ & $25.35 \pm 1.30^{\mathrm{c}}$ \\
\hline
\end{tabular}

Values followed by the same superscript alphabet on the same row are not significantly different at $\mathrm{P}>0.05$ level of significance. Values are pr esented in mean \pm standard error, Control =Aquama conventional feed; $5 \%=5 \%$ of $S$. cerevisiae $; 10 \%=10 \%$ of $S$. cerevisiae and $15 \%=15 \%$ of $S$. cerevisiae.

The physico chemical parameters of cultured water of Heteroclarias juveniles fed different levels of $S$. cerevisiae diets are presented in Table 4. S. cerevisiae diets and control diet had no significant influence $(\mathrm{P}>0.05)$ on water temperature, $\mathrm{pH}$ and dissolved Oxygen concentration. The biochemical Oxygen demand of the cultured media of Heteroclarias juveniles was however, significantly $(\mathrm{P}<0.05)$ affected among the treatments. It ranged from $0.23 \pm 0.03$ in the control diet to $0.40 \pm$ $0.00 \mathrm{mg} / 1$ at $10 \% \mathrm{~S}$. cerevisiae diet. However, the BOD $(0.23 \pm 0.33 \mathrm{mg} / \mathrm{l})$ of the cultured media of juveniles fed control diet was lowest $(\mathrm{p}<0.05)$ at the end of the study

Table $4:$ Mean $\pm \mathrm{s}$ tandard error of the physico-chemical parameters of cultured media of Heteroclarias juveniles fed different level of Saccharomyces cerevisiae diet for a period of eight (8) weeks

\begin{tabular}{lllll}
\hline Diet levels & Temp $\left({ }^{\circ} \mathrm{C}\right)$ & $\mathrm{pH}$ & $\mathrm{D} . \mathrm{O}(\mathrm{mg} / \mathrm{l})$ & $\mathrm{BOD}(\mathrm{mg} / \mathrm{l})$ \\
\hline Control & $28.00 \pm 0.00^{\mathrm{a}}$ & $7.23 \pm 0.03^{\mathrm{a}}$ & $2.00 \pm 0.00^{\mathrm{a}}$ & $0.23 \pm 0.03^{\mathrm{d}}$ \\
$5 \%$ & $28.00 \pm 0.00^{\mathrm{a}}$ & $7.10 \pm 0.00^{\mathrm{a}}$ & $2.00 \pm 0.00^{\mathrm{a}}$ & $0.37 \pm 0.03^{\mathrm{b}}$ \\
$10 \%$ & $28.00 \pm 0.00^{\mathrm{a}}$ & $7.10 \pm 0.00^{\mathrm{a}}$ & $2.00 \pm 0.00^{\mathrm{a}}$ & $0.40 \pm 0.00^{\mathrm{a}}$ \\
$15 \%$ & $28.00 \pm 0.00^{\mathrm{a}}$ & $7.10 \pm 0.00^{\mathrm{a}}$ & $2.00 \pm 0.00^{\mathrm{a}}$ & $0.33 \pm 0.03^{\mathrm{c}}$ \\
\hline
\end{tabular}

Values followed by the same superscript alphabet on the same column are not significantly different at $\mathrm{P}>0.05$ level of significance. Values are presented in mean \pm standard error of two determinants; Control $=$ Aquamax conventional feed; $5 \%=5 \%$ of $S$. cerevisiae; $10 \%=10 \%$ of $S$. cerevisiae and $15 \%=15 \%$ of $S$. cerevisiae.

The proximate composition of Heteroclarias juveniles fed different levels of $S$. cerevisiae diets for a period of eight (8) weeks are presented in Table 5. The moisture content of the juveniles fed control diet was significantly $(p<0.05)$ higher (7.78 \pm 0.01 ) while juveniles fed $10 \% S$. cerevisiae had lower moisture content (6.26 \pm 0.02). Juveniles fed control diet however, had lower $(\mathrm{p}<0.05)$ values of ash $(2.15 \pm 0.01)$ and crude protein $(45.00 \pm$ $0.58)$. Juveniles fed $15 \%$ S cerevisiae diet had better $(\mathrm{p}<0.05)$ ash and oil extracts $(2.50 \pm 0.06$ and $13.93 \pm 0.15$, respectively). In terms of crude protein, juveniles fed 5,10 and $15 \%$ S. cerevisiae diets had similar ( $\mathrm{p}>$ $0.05)$ values. 


\section{Ayanwale, Ogbonnaya, Arimoro, Unique and Chukwuemeka}

Table 5: Mean \pm standard error of the proximate composition of Heteroclarias fed different levels of Saccharomyces cerevisiae diet for a period of eight (8) weeks

\begin{tabular}{lllll}
\hline Diet level & Moisture & Ash & Crude protein & Oil extract \\
\hline Control & $7.78 \pm 0.01^{\mathrm{a}}$ & $2.15 \pm 0.01^{\mathrm{c}}$ & $45.00 \pm 0.58^{\mathrm{c}}$ & $12.80 \pm 0.06^{\mathrm{c}}$ \\
$5 \%$ & $7.17 \pm 0.07^{\mathrm{c}}$ & $2.35 \pm 0.01^{\mathrm{b}}$ & $45.55 \pm 0.08^{\mathrm{b}}$ & $11.60 \pm 0.06^{\mathrm{d}}$ \\
$10 \%$ & $6.26 \pm 0.02^{\mathrm{d}}$ & $2.39 \pm 0.02^{\mathrm{b}}$ & $47.25 \pm 0.01^{\mathrm{a}}$ & $13.30 \pm 0.17^{\mathrm{b}}$ \\
$15 \%$ & $7.55 \pm 0.01^{\mathrm{b}}$ & $2.50 \pm 0.06^{\mathrm{a}}$ & $48.13 \pm 0.01^{\mathrm{a}}$ & $13.93 \pm 0.15^{\mathrm{a}}$ \\
\hline
\end{tabular}

Values followed by the same superscript alphabet on the same column are not significantly different at $\mathrm{P}>0.05$ level of significance. Values are presented in mean \pm standard error of two determinants; Control $=$ Aquamax conventional feed; $5 \%=5 \%$ of $S$. cerevisiae; $10 \%=10 \%$ of $S$. cerevisiae and $15 \%=15 \%$ of $S$. cerevisiae.

The results of percentage survival rate of the Heteroclarias juveniles fed different levels of $S$. cerevisiae for a period of eight (8) weeks are presented in Table.6. The percentage survival rate of Heteroclarias juveniles fed $5 \%$ supplementary $S$. cerevisiae diet $(97 \%)$ was significantly $(\mathrm{p}<0.05)$ higher than those of other treatments. However, the juveniles fed control diet had lower $(\mathrm{p}<0.05)$ percentage survival rates $(77 \%)$ at the end of the study.

Table 6: Percentage s urvival of Heteroclarias juveniles fed different levels of Saccharomyces cerevisiae diet for a period of eight $(8)$ weeks

\begin{tabular}{ll}
\hline Diet level & Percentage Survival (\%) \\
\hline Control & $77.00^{\mathrm{d}}$ \\
$5 \%$ & $97.00^{\mathrm{a}}$ \\
$10 \%$ & $87.00^{\mathrm{b}}$ \\
$15 \%$ & $83.00^{\mathrm{c}}$ \\
\hline
\end{tabular}

Values followed by the same superscript alphabet on the same column are not significantly different at $\mathrm{P}>0.05$ level of significance. Values are presented in mean \pm standard error of two determinants; Control = Aquamax conventional feed; $5 \%=5 \%$ of $S$. cerevisiae; $10 \%=10 \%$ of $S$. cerevisiae and $15 \%=15 \%$ of $S$. cerevisiae

The total length of Heteroclarias juveniles was not influenced by the dietary treatments in weeks 1 and 3 . This could be attributed to the adjustment of the microflora in the gastro intestinal tract of the fishes gradually, which became adjusted to the control and different levels of $S$. cerevisiae diets (Sahu et al., 2008). The longest TL and SL recorded in the Heteroclarias juveniles fed with $10 \% S$. cerevisiae diet from weeks $4,5,6$ and 8 suggest that probiotics might improve digestion by stimulating production of digestive enzymes or through other alterations in the gut environment, which could translate to improved growth performance (Welker and Lim 2011). The yeast could also be attached to the gut when supplied by food which may lead to improved amylase secretion and stimulation of brush border membrane enzymes. Perhaps, enhancement of growth and food utilization by the fish may be due to improvement of nutrient digestibility (Lara-Flores et. al, 2003). Abdelhamid et al. (2004) also found that probiotics (Betafin and Biopolym) not only increased body weight, growth rates and total productivity of African catfish fingerlings, but also improved the percentage of muscular protein. Moreover, the study of Wache et al. (2006) showed that addition of live yeast can improve diet and protein digestibility which may account for better growth and 
food efficiency. Also, similar results were reported by Lashkar Boloki et al. (2011) in persian sturgen (Acipenser persicus). Growth improvement has been reported by feeding of $S$. cerevisiae in Oreochromis niloticus (Lara-Flores et al. 2003; Asadi et al.2012).

The digestive tract of hydrobionts is an open system constantly interacting with the surrounding environment. As a result, the establishment, proliferation and function of the probiotics in the digestive tract are largely influenced by various environmental factors, such as water quality, hardness, dissolved oxygen, temperature, $\mathrm{pH}$, osmotic pressure, mechanical friction and the environmental microflora (Das et al., 2008; Mehrim,2009; Ai et al., 2011). The water temperature, $\mathrm{pH}$, and dissolved Oxygen (DO) of the cultured media of Heteroclarias juveniles recorded in this study agreed with the works of Kazaure et al. (2015) who documented that probiotics had no influence on the physico chemical parameters of the rearing media of $C$. gariepinus. The $\mathrm{pH}$ range of the rearing media obtained was in agreement with the findings of Ivoke et al. (2007) that the ideal $\mathrm{pH}$ range for the growth and survival of fish was between 6- 9 . Similarly, Bryan (2004) also stated that most fishes can tolerate $\mathrm{pH}$ range of 6-9 for effective growth and survival. The rearing media of juveniles fed control diet had a lower BOD, but Patricia et al. (2012) noted that probiotics can be used to improve water quality when high concentrations of nitrogen compounds, such as toxic total ammonia are produced. The values recorded fell below 1-5mg/1 which indicated no organic pollution in the rearing water (Centre for Innovation in Engineering and Science Education (CIESE, 2009).

S. cerevisiae supplementation significantly affected the whole-fish body moisture, ash, protein and lipid contents of Heteroclarias juveniles. Abdel-Tawwab et al. (2008) suggested that yeast supplementation played a role in enhancing food intake with a subsequent enhancement of fish body composition. Moreover, due to the nutrient utilization and the high nutrient digestibility, the deposited nutrients increased. Also, changes in protein and lipid content in fish body could be linked with changes in their synthesis, deposition rate in muscle and/or different growth rate (Abdel-Tawwab et al., 2006; 2008). The findings of this study are in agreement with the works of Abdel-Tawwab et. al. (2008) that fish fed control diet had the lowest protein content. It is however contrary to the works of Diab et al. (2002) and Mohammed et al. (2007) that the use of Saccharomyces cerevisiae diets had no influence on the moisture, crude protein, ash and lipid contents of the experimental groups. The highest percentage (97\%) recorded in the survival rate of Heteroclarias juveniles fed with 5\% level of $S$. cerevisiae diet was in agreement with the works of Wang et al. (2004) who observed that the use of probiotics like $S$. cerevisiae improves the survival rate of African catfish by improving their immune system. In addition, Heteroclarias juveniles fed with $5 \%$ S. cerevisiae diet might have had micro flora in the intestinal tract with beneficial microorganisms which led to increase in their survival rate. The lowest percentage survival rate observed in the juveniles fed with the control diet could be as a result of their decreased potential to tolerate harmful conditions that fish may be exposed to in culture tanks as affirmed by Rollo et al. (2006) in Sparus aurata (Sea bass). The authors affirmed the least survival rate observed in juveniles fed with control diet to be attributed to the absence of beneficial microorganisms in their intestinal tract. 


\section{Conclusion}

The results of the present study indicated clearly that the supplementation of fish diets, S. cerevisiae (10\%) enhanced the growth rate as measured by total length, standard length and body weight of Heteroclarias juveniles. Water temperature, dissolved oxygen and water $\mathrm{pH}$ were not influenced by the dietary treatments. Biochemical oxygen demand, proximate composition and the survival rates of Heteroclarias juveniles were influenced by the diet treatments.

\section{References}

Abdelhamid, A. M., Abd El-Khalil, A. E., Mostafa, M. A. A., Gomaah, S. A. A. and Khalil, F. F. 2004. Effect of using betafin and/or Biopolym as natural additives in producing nile tilapia fish in poly-culture semiintensive system in earthen ponds. J. Agric. Sci. Mansoura Univ.; 29:3149-3162.

Abdel-Tawwab, M., Khattab, Y. A. E., Ahmad, M. H. and Shalaby, A. M. E. 2006. Compensatory growth, feed utilization, whole body composition and haematological changes in starved juvenile Nile tilapia, Oreochromis niloticus (L.). Journal of Applied Aquaculture. 18:17-36.

Abdel-Tawwab, M., Abdel-Rahman, A. M. and Ismael, N. E.M 2008. Evaluation of Commercial live baker's Yeast, Sacharomyces cerevisiae a growth and immunity promoters for fry Nile Tilapia Oreochromis niloticus Challenged in situ with Aeromonas hydrophila. Aquaculture, 280:185189.

Adewolu, M. A., Ogunsanmi, A. O. and Yunusa, A. 2008. Studies on growth performance and feed utilization on two Clarid Catfish
IQ and their hybrid reared under different culture systems. European Journal of Scientific Research. 23(2): 252-260.

Ai, Q., Xu, H., Mai, K., Xu, W., Wang, J. and Zhang, W. 2011. Effects of dietary supplementation of Bacillus subtilis and fructooligosaccharide on growth performance, survival, nonspecific immuneresponse and disease resistance of juvenile large yellow croaker, Larimichthys crocea. Aquaculture.317:155161.

AOAC 2006. Association of Official Analytical Chemists Official Methods of Analysis. International; 18th. Arlington, Va, USA.

Asadi, R., Mohammad, Z., Mohammad, Y., Vahid, M. and Seyed, M. 2012. Effect of different levels of dietary supplementation of saccharomyces cerevisiae on growth performance, feed utilization and body biochemical composition of nile tilapia (oreochromis niloticus) fingerlings Journal of the Persian Gulf (Marine Science)/Vol. 3/No. 9/15-24.

Axiel, B. 2010. Hach Company. Laboratory product application management Electrochemistry. www.hach.com/probes .pp 132.

Ayanwale, A. V., Tsadu, S. M., Kolo, R. J., Lamai, S. L., Falusi, F. M. and Baba, B. M. 2014. Advance in Agriculture and Biology. 1(3): 135-139.

Bryan, R., 2004. Technical and Memorandum; $\mathrm{pH}$ requirements of fresh water aquatic life. Robertson -Bryan Inc. 9766. Waterman Road, Suite L2, E/K Grove, CA. 95624(916), 714-1802. 
Supplementing different levels of Saccharomyces cerevisiae diets on survival and some growth parameters

Buntyn, J. O., Schmidt, T. B., Nisbet, D. J. and Callaway, T. R. 2016. The Role of Direct-Fed Microbials in Conventional Livestock Production Annu Rev Anim Biosci. ; 4:335-55. doi: 10.1146/annurev-animal-022114111123.

CIESE 2009. Centre for Innovation in Engineering and Science Education. Biological Oxygen Demand Stevens Institute in Africa. 26:31-35

Das, S., Ward, L. R. and Burke, C. 2008. Prospects of using marine Actinobacteria as probiotics in a quaculture. Applied Microbiology and Biotechnology 81:419-429.

Diab, A. S., EL-Nagar, O. G. and Abd-ElHady, M. Y. 2002. Evaluation of Nigella sativa L. (black seeds; baraka), Allium sativum (garlic) \& Biogen as a feed additives on growth performance of Oreochromis niloticus fingerlings. Vet.Med. J.; 2:745-753.

Dong Han, S., Xie Wu, L., Xiaoming, Z. and Yunxia, Y. 2005. Effect of Light Intensity On Growth Survival and Skin Colour of Juvenile Chinese Longsnout Catfish (Leiocassis longirostris Gunther). Aquaculture, 248, 299306.

Duncan, D. B. 1955. New multiple and multiple F-test. Biometric, 11, 142.

Irianto, A. and Austin B. 2002. Use of probiotics to control furunculosis in rainbow trout, Oncorhynchus mykiss (Walbaum). Journal of Fish Diseases 25: 333-342.

Ivoke, N., Mgbenka, B. O. and Okeke, O. 2007. Effect of $\mathrm{pH}$ on the Growth Performance of Heterobranchus bidorsalis X Clarias gariepinus Hybrid Juveniles, .Animal Research International, 4(1), 639642.

Kazaure, S. Z., Isa1, H. A., Mohammed, Y., and Namadi, M. M. 2015. Comparative analysis of physicochemical parameters and heavy metals of public water supply in Kaduna metropolis. Journal of Applied Chemistry. 8(11), 21-26.

Lara-Flores, M., Olvera-Novoa, M. A., Guzman-Mendez, B. E., and Lopez-Madrid, W. 2003. Use of the bacteria Streptococcus faecium and Lactobacillus acidophilus, and the yeast Saccharomyces cerevisiae as growth promoters in Nile tilapia (Oreochromis niloticus). Aquaculture 216, 193 201.

Lashkar Boloki M., Jafaryan, H., Faramarzi, M. and Adineh, $\mathbf{H}$. 2011. The effects of Amax yeast live and dead probiotic cells in tilapia Oreochromis niloticus. Fisheries Sciences magna. AACL Bioflux 4(3):361-367.

Mehrim, A. I. 2009. Effect of dietary supplementation of Biogen (Commercial probiotic) on monosex Nile tilapia Oreochromis niloticus under different stocking densities. Journal of Fisheries and AquaticScience. 4(6):261-273.

Mohamed, K. A., Abdel Fattah, B. and Eid, A. M. S. 2007. Evaluation of using some feed additives on growth performance and feed utilization of monosex Nile Tilapia (Oreochromis niloticus) fingerlings. Agric. Res. J.; 7:49-54.

Mona, M. H., Alm-Eldeen, A. A., Elgayar, E. E., Heneish, A. M. and El-feky, M. M. 2015. Evaluation the Effect of 
Ayanwale, Ogbonnaya, Arimoro, Unique and Chukwuemeka

Local and Imported Yeasts as Supplementary Food on the African Catfish (Clarias gariepinus) in Egypt. J Aquac Mar Biol 2(3): 00024. DOI: 10.15406/jamb.2015.02.00024

NSADP 2007. Niger State Agricultural Development Project. An insight into the Agricultural activities of Niger State, Minna, 2007 Edition.

Okeke P. A 2014. Studies on the effects of stocking densities on growth performance and survival level of Heteroclarias (hybrid). International Journal for Agriculture and Biological sciences 3(3): 136-140.

Olagunju, F. I., Adesiyan, I. O., and Ezekiel A. A. 2007. Economic Viability of cat fish production in Oyo State, Nigeria. Journal of Human Ecology. 21(2): 121-124.

Olufayo, M. O. 2009. Haematological characteristics of Clarias gariepinus (burchell, 1822) juveniles exposed to derris elliptica root powder. African Journal of Food Agriculture, Nutrition and Development, 9 (3), 920-933.

Patricia, M. C., Ana, L. I., Oscar, A., Monroy, H. and Hugo C. R. S. 2012. Use of Probiotics in Aquaculture. ISRN Microbiol. Published online 2012 Oct 16. doi: 10.5402/2012/916845.

Rollo, A., Sulpizio, R., Nardi, M., Silvi S., Orpianesi, C., Caggiano, M., Cresci, A. and Carnevali, $O$. 2006. Live microbial feed supplement inaquaculture for improvement of stress tolerance. Journal of Fish Physiology and Biochemistry 32,167-177.

Sahu, M. K., Swarnakumar, N. S., Sivakumar, K., Thangaradjou, T. and Kannan, L. 2008. Probiotics in aquaculture: importance and future perspectives. Indian Journal of Microbiology 48, 299-308.

Santini, C., Baffoni, L., Gaggia, F., Granata, M., Gasbarri, R., di Gioia, D. and Biavati, B. 2010. Characterization of probiotic strains: An application as feed additives in poultry against Campylobacter jejuni. Int. J. Food Microbiol., 141: 98-108.

Taoka, Y., Maeda, H., Jo, J. Y., Kim, S. M., Park, S. I., Yoshikawa, T., Sakata, T., Waché, Y., Auffray, F., Gatesoupe, F. J., Zambonino, J., Gayet, V., Labbé, L. and Quentel, C. 2006. Use of Cross effects of the strain of dietary Saccharomycescerevisiae and rearing conditions on the onset of intestinal microbiota and digestive enzymes inrainbow trout, Onchorhynchus mykiss fry.Aquaculture. 258:470-478.

Wang, K. Y., Li, S. N., Liu, C. S., Perng, D. S., Su, Y. C., Jan, D. C., Lai, C.M., Wang, C. H. and Wang, W. M. 2004. Effect of ingesting $L$ a c to b a c i l l us a n d Bifidobacterium containing yoghurt in subjects with colonized Helicobacter pylori. American Journal of Clinical Nutrition 80: 737-741.

Welker, T.L. and Lim, C. 2011. Use of probiotics indiets of tilapia. Journal of Aquauclture Research and Development. S1:014. doi:10.4172/2155.72;755 - 766, 9546.S1-014.

Received: $20^{\text {th }}$ June, 2020 Accepted: $4^{\text {th }}$ October, 2020 